\title{
The Effect of Acute and Chronic Ethanol on Dopamine Turnover in the Caudate Nucleus of the Rat
}

\author{
Rif S. El-Mallakh, MD \\ University of Connecticut Health Center, Farmington Connecticut
}

Follow this and additional works at: https://jdc.jefferson.edu/jeffjpsychiatry

Part of the Psychiatry Commons

Let us know how access to this document benefits you

\section{Recommended Citation}

El-Mallakh, MD, Rif S. (1988) "The Effect of Acute and Chronic Ethanol on Dopamine Turnover in the Caudate Nucleus of the Rat," Jefferson Journal of Psychiatry. Vol. 6 : Iss. 1 , Article 7.

DOI: https://doi.org/10.29046/JJP.006.1.005

Available at: https://jdc.jefferson.edu/jeffjpsychiatry/vol6/iss1/7

This Article is brought to you for free and open access by the Jefferson Digital Commons. The Jefferson Digital Commons is a service of Thomas Jefferson University's Center for Teaching and Learning (CTL). The Commons is a showcase for Jefferson books and journals, peer-reviewed scholarly publications, unique historical collections from the University archives, and teaching tools. The Jefferson Digital Commons allows researchers and interested readers anywhere in the world to learn about and keep up to date with Jefferson scholarship. This article has been accepted for inclusion in Jefferson Journal of Psychiatry by an authorized administrator of the Jefferson Digital Commons. For more information, please contact: JeffersonDigitalCommons@jefferson.edu. 


\title{
The Effect of Acute and Chronic Ethanol on Dopamine Turnover in the Caudate Nucleus of the Rat
}

\author{
Rif S. El-Mallakh, M.D.
}

It is generally believed that acute and chronic ethanol (EtOH) administration alters the activity of catecholamines in the brain, however, the specific effects of $\mathrm{EtOH}$ on the dopaminergic system are disputed (1). Acute EtOH administration has been variously reported to decrease $(2,3)$, increase $(4,5)$, and cause no change $(6,7)$ in dopamine (DA) synthesis and turnover. Likewise, chronic EtOH treatments have been reported to decrease $(2,8)$ and increase $(9,10)$ DA synthesis and turnover. Many of these apparently conflicting results are explained by the use of different animal models (rat $(2,3,6,7,10)$, rabbit (6), and mouse $(4,5,9)$ ), different methods of EtOH administration (intraperitoneal $(3,4,6,7)$, oral $(2,5)$, and inhalation $(9))$, and no assurance of alcoholic dependence with chronic exposure $(2,10)$. Further, the majority of these studies were carried out prior to the development of a very sensitive high performance liquid chromatography (HPLC) technique which can detect minute amounts of DA, dihyroxyphenylalanine (DOPA), and dihydroxyphenylacetic acid (DOPAC) $(11,12)$.

Since DA receptor supersensitivity has been found in the mesolimbic system of EtOH-dependent rats $(1,13)$ and because EtOH increases DA release in vivo (14) (indicating that EtOH does affect the dopaminergic system), we elected to examine the effects of acute and chronic EtOH administration on the dopaminergic system in the rat caudate nucleus.

\section{MATERIALS AND METHODS}

Male Sprague-Dawley rats (250-300 gms) were purchased from ARS/ Sprague-Dawley, Madison, Wisconsin, and housed five to a cage (temperature $22 \pm 1 \mathrm{C}, 0700-1900$ hour light cycle) for at least 10 days prior to experimentation. EtOH-dependent animals were obtained by using a modified inhalation method (15-17). Inhalation chambers, constructed of clear plexiglass and measuring approximately $120 \times 150 \times 90 \mathrm{~cm}$ (i.e., large enough for two standard large rat cages), were used. $\mathrm{EtOH}$ vapor, produced by bubbling room air through $95 \%$ EtOH by way of fishtank air pumps, was maintained at the

Dr. El-Mallakh is a third year resident in psychiatry at the Department of Psychiatry, University of Connecticut Health Center, Farmington, Connecticut. 
concentration of $16-20 \mathrm{mg} /$ liter of chamber air. This resulted in tail blood ethanol concentrations of $200-350 \mathrm{mg} / \mathrm{dl}$. The animals were placed five to a cage (10 to a chamber) for four to six days. The rats were then removed and observed for signs of alcoholic withdrawal every four hours over the course of a for 16 hour period.

A semi-quantitative assessment of physical dependence based on previously published scales (18) was made. The rats were scored for the following: tail rigidity ( 1 point), head and caudal tremors ( 2 points each), chattering ( 2 points), wide-legged stance ( 2 points), hypothermia (1 point/each ${ }^{\circ} \mathrm{C}$ below 37 ) (19), audiogenic seizures (induced by shaking keys above cage) (5 points), and spontaneous seizures (10 points). The point assignment was designed so that animals scoring a minimum of 10 points would be definitely physically dependent on ethanol. Consequently, only animals scoring at least 10 points were used in the experiments.

Chamber air and rat blood EtOH concentration were measured using a previously described gas chromatographic method (20). Rat body temperature was measured by inserting a lubricated probe of a Telethermometer (Yellow Springs Instrument Company, Yellow Springs, Ohio) $2.5 \mathrm{~cm}$ into the rectum.

Four groups of animals were tested: 1) ethanol withdrawal-ethanol challenge, 2) ethanol withdrawal-saline challenge, 3) naive animals-ethanol challenge (i.e., acute $\mathrm{EtOH}$ ), and 4) naive animals-saline challenge (i.e., controls).

Twenty-four hours post-initiation of withdrawal the groups of experimental and control animals were challenged with intraperitoneal (IP) injections of $\mathrm{EtOH}$ or saline (1.35 gm $\mathrm{EtOH} / \mathrm{kg}$ body weight). This was followed in 10 minutes by an IP injection of NSD-1024 (500 mg/ kg) (3-hydroxybenzyloamine dihydrogen phosphate is a brain aromatic amino acid decarboxylase inhibitor; Sandev Ltd, Gilston Park, Sussex, England). Thirty minutes after the challenge dose, the rats were decapitated. The brains were gently removed from the skull and disected over ice $(4 \mathrm{C})$. An axial section at the level of the lateral olfactory stria and another, $2 \mathrm{~mm}$ caudally, were made to obtain a slice of brain which contained most of the caudate nucleus. The caudate was disected out and homoginized in $5.0 \mathrm{ml}$ of $0.4 \mathrm{~N}$ perchloric acid containing $0.05 \%$ sodium sulfate, $0.2 \%$ EDTA, and 2 nmol DHBA (3,4,dihydroxybenzylamine) to serve as an internal standard. DA, DOPA, and DOPAC were extracted (11) and their levels determined by a high performance liquid chromatography (HPLC) technique $(11,12)$.

\section{Blood Gases}

Since $\mathrm{EtOH}$ vapors may cause local irritation and dehydration of lung tissue (21), it was elected to test the effect of ethanol on the oxygenation of blood. Adult male Black Norway rats were anesthestized with $40 \mathrm{mg} / \mathrm{kg}$ nembutol. A $2 \mathrm{~cm}$ longitudinal incision was made over the ventral neck surface. One of the carotid arteries was isolated, ligated, and transected. The distal stub 
TABLE 2.

DOPA, DA, and DOPAC Levels in Animals Studied (all levels are in nmoles/mg wet weight caudate tissue \pm standard error).

\begin{tabular}{cccc}
\hline & DOPA & DA & DOPAC \\
\hline EtOH Withdrawal-EtOH & $0.0143 \pm 0.0023$ & $0.417 \pm 0.0763$ & $0.00849 \pm 0.0012$ \\
Challenge & $(\mathrm{n}=4)$ & $(\mathrm{n}=3)$ & $(\mathrm{n}=4)$ \\
EtOH Withdrawal-Saline & $0.0132 \pm 0.00205$ & $0.564 \pm 0.063$ & $0.0142 \pm 0.00175$ \\
Challenge & $(\mathrm{n}=4)$ & $(\mathrm{n}=4)$ & $(\mathrm{n}=4)$ \\
Control-EtOH Challenge & $0.01 \pm 0.0023$ & $0.278 \pm 0.0353$ & $0.00414 \pm 0.00063$ \\
& $(\mathrm{n}=3)$ & $(\mathrm{n}=3)$ & $(\mathrm{n}=3)$ \\
Control-Saline Challenge & $0.00832 \pm 0.00071$ & $0.369 \pm 0.0357$ & $0.00628 \pm 0.00057$ \\
& $(\mathrm{n}=4)$ & $(\mathrm{n}=4)$ & $(\mathrm{n}=4)$ \\
\hline
\end{tabular}

ethanol challenged animals. This group of animals closely approximates chronic ethanol consumption since ethanol challenge reestablishes the pre-withdrawal equilibrium. The dopaminergic neurons' tolerance to the depressive effects of chronic ethanol is apparently achieved, at least in part, by a comparative hyperactivity of the dopaminergic system. This effect becomes unmasked when $\mathrm{EtOH}$ is cleared from the body (EtOH dependent-saline challenge).

\section{DISCUSSION}

In performing these experiments, we attempted to avoid problems which had plagued earlier studies. We elected to use the inhalation method of EtOH administration because it was found to be superior to other methods (23). Steady state levels of a neurotransmitter may not always reflect actual rate of its turnover $(6,24)$, and previously used fluorimetric methods for measuring DOPA were too insensitive to accurately evaluate decrease in DOPA (12). We therefore measured DOPA, DA, and DOPAC using a very sensitive HPLC method $(11,12)$ to get an accurate idea of dopamine turnover and tyrosine hydroxylase activity. Finally, since different strains of mice have been found to respond differently to $\mathrm{EtOH}$ (25), we elected to work with Sprague-Dawley rats because they possess genetic heterogeniety.

Our results indicated that acute $\mathrm{EtOH}$ has a depressive effect on the dopaminergic system. Chronic EtOH administration apparently produces a tolerance to this depressive effect. This tolerance is achieved, in part, by comparative hyperactivity of the dopaminergic system. This hyperactivity, evident in increased DA and DOPAC levels and increased activity of tyrosine hydroxylase (i.e., increased DOPA), is seen during EtOH withdrawal after EtOH has been cleared from the body.

These results agree with most $(2,3,10)$, but not all $(2,6,7)$, previous work done with the rat; and is different from results obtained from the mouse $(4,5,9)$ and rabbit (6). Our results also appear to be consistent with the dopamine 
DOPA, DA, DOPAC

The levels of DOPA, DA, and DOPAC in the rat caudate nucleus are presented in Figure 1 and Table 2. The data for DA and DOPAC show clear trends, but the small number of animals in each group (Table 2), does not allow for reliable statistical analysis. The data for DOPA shows such variation that no clear conclusion can be drawn from them.

NSD-1024 is a brain aromatic amino acid decarboxylase inhibitor (22) and consequently, causes accumulation of DOPA. This would normally serve as a measure of tyrosine hydroxylase activity which is the rate limiting step of DA synthesis. Likewise, the depletion of DA and accumulation of DOPAC are measures of the activity of the dopaminergic neurons. As indicated in Figure 1 and Table 2, acute ethanol administration to naive animals causes a decrease in dopaminergic activity (i.e., a decrease in DA turnover), manifest by the low levels of DA and lack of accumulation of DOPAC. Chronic administration of $\mathrm{EtOH}$ produces tolerance to this depressive effect of $\mathrm{EtOH}$ as indicated by increased levels of DA and accumulation of DOPAC in ethanol withdrawal-
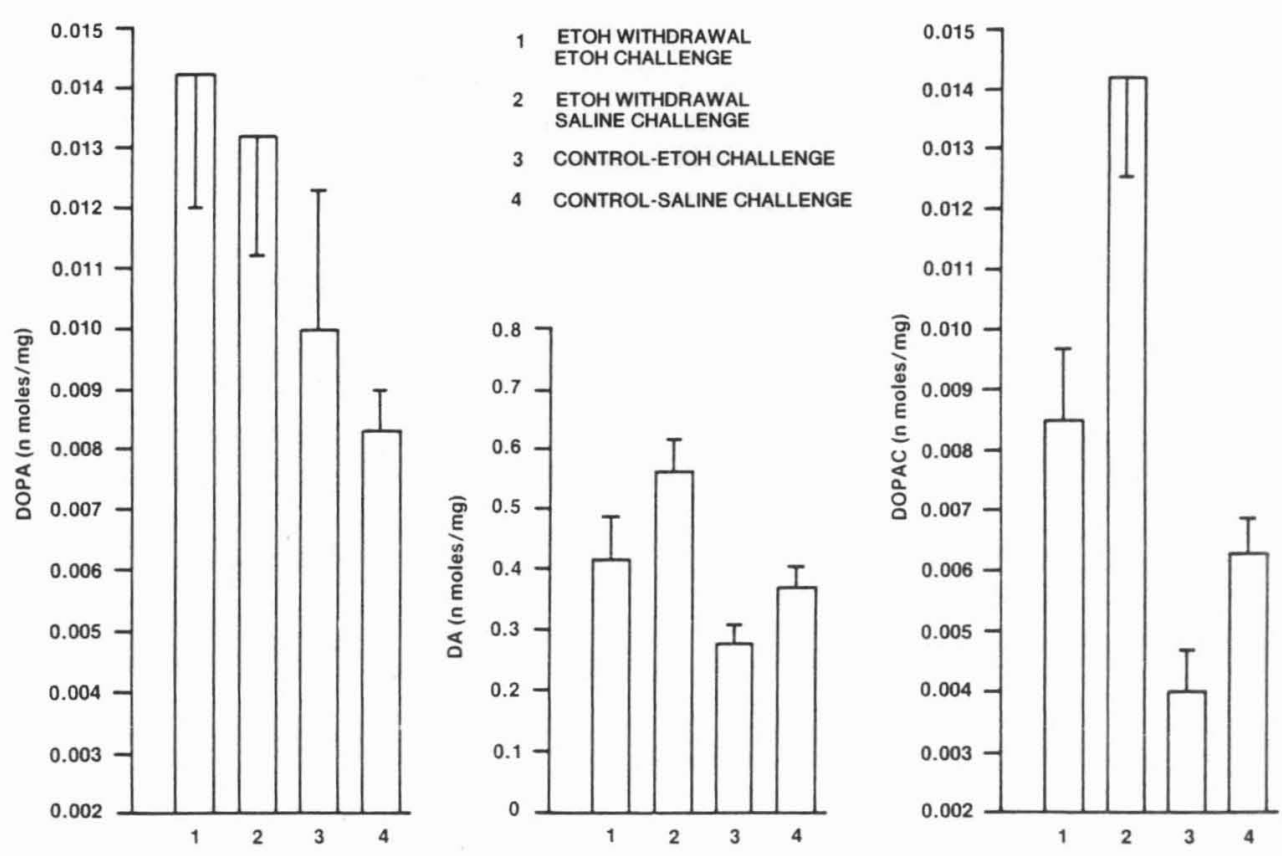

FIGURE 1. DOPA, DA, and DOPAC levels in the caudate nucleus (nmoles/mg caudate \pm S.E.) of rat:

1) Ethanol withdrawal-ethanol challenge

2) Ethanol withdrawal-saline challenge

3) Control-ethanol challenge

4) Control-saline challenge 
TABLE 2.

DOPA, DA, and DOPAC Levels in Animals Studied (all levels are in nmoles/mg wet weight caudate tissue \pm standard error).

\begin{tabular}{cccc}
\hline & DOPA & DA & DOPAC \\
\hline EtOH Withdrawal-EtOH & $0.0143 \pm 0.0023$ & $0.417 \pm 0.0763$ & $0.00849 \pm 0.0012$ \\
Challenge & $(\mathrm{n}=4)$ & $(\mathrm{n}=3)$ & $(\mathrm{n}=4)$ \\
EtOH Withdrawal-Saline & $0.0132 \pm 0.00205$ & $0.564 \pm 0.063$ & $0.0142 \pm 0.00175$ \\
Challenge & $(\mathrm{n}=4)$ & $(\mathrm{n}=4)$ & $(\mathrm{n}=4)$ \\
Control-EtOH Challenge & $0.01 \pm 0.0023$ & $0.278 \pm 0.0353$ & $0.00414 \pm 0.00063$ \\
& $(\mathrm{n}=3)$ & $(\mathrm{n}=3)$ & $(\mathrm{n}=3)$ \\
Control-Saline Challenge & $0.00832 \pm 0.00071$ & $0.369 \pm 0.0357$ & $0.00628 \pm 0.00057$ \\
& $(\mathrm{n}=4)$ & $(\mathrm{n}=4)$ & $(\mathrm{n}=4)$ \\
\hline
\end{tabular}

ethanol challenged animals. This group of animals closely approximates chronic ethanol consumption since ethanol challenge reestablishes the pre-withdrawal equilibrium. The dopaminergic neurons' tolerance to the depressive effects of chronic ethanol is apparently achieved, at least in part, by a comparative hyperactivity of the dopaminergic system. This effect becomes unmasked when $\mathrm{EtOH}$ is cleared from the body (EtOH dependent-saline challenge).

\section{DISCUSSION}

In performing these experiments, we attempted to avoid problems which had plagued earlier studies. We elected to use the inhalation method of $\mathrm{EtOH}$ administration because it was found to be superior to other methods (23). Steady state levels of a neurotransmitter may not always reflect actual rate of its turnover $(6,24)$, and previously used fluorimetric methods for measuring DOPA were too insensitive to accurately evaluate decrease in DOPA (12). We therefore measured DOPA, DA, and DOPAC using a very sensitive HPLC method $(11,12)$ to get an accurate idea of dopamine turnover and tyrosine hydroxylase activity. Finally, since different strains of mice have been found to respond differently to $\mathrm{EtOH}$ (25), we elected to work with Sprague-Dawley rats because they possess genetic heterogeniety.

Our results indicated that acute $\mathrm{EtOH}$ has a depressive effect on the dopaminergic system. Chronic EtOH administration apparently produces a tolerance to this depressive effect. This tolerance is achieved, in part, by comparative hyperactivity of the dopaminergic system. This hyperactivity, evident in increased DA and DOPAC levels and increased activity of tyrosine hydroxylase (i.e., increased DOPA), is seen during $\mathrm{EtOH}$ withdrawal after $\mathrm{EtOH}$ has been cleared from the body.

These results agree with most $(2,3,10)$, but not all $(2,6,7)$, previous work done with the rat; and is different from results obtained from the mouse $(4,5,9)$ and rabbit (6). Our results also appear to be consistent with the dopamine 
receptor supersensitivity observed in ethanol-dependent rats $(1,13)$. One could envision that both DA receptor supersensitivity and increased DA turnover would both participate in overcoming the depressive effects of $\mathrm{EtOH}$ on this system. Incorporation of these results into the clinical picture of human ethanol dependence and withdrawal must await a better understanding not only of how the dopaminergic system interacts with other neurotransmitter systems, but also a better understanding of the similarities between human and rat brains.

\section{ACKNOWLEDGEMENTS}

I would like to thank Boris Tabakoff, Ph.D., then of the Department of Physiology and Biophysics, University of Illinois, for his invaluable help, support, and teaching. I would also like to thank Michael Kapin, Ph.D., also of the Department of Physiology and Biophysics, for his help in performing the carotid catheterizations. This work was supported, in part, by a grant from the National Institute of Alcohol Abuse and Alcoholism to Dr. Tabakoff, and by a University of Illinois research fellowship to Dr. El-Mallakh.

\section{REFERENCES}

1. Tabakoff B, Hoffman PL: Alcohol and neurotransmitters, in Alcohol Tolerance and Dependence. Edited by Rigter H and Crabbe J. Elsevier, Amsterdam, 1980

2. Hunt WA, Majchrowicz E: Alterations in the turnover of brain norepinephrine and dopamine in alcohol-dependent rats. J Neurochem 1974; 23:549-552

3. Bacopoulos NG, Bhatnagar RK, van Orden LS: The effects of subhypnotic doses of ethanol on regional catecholamine turnover. J Pharmacol Exp Therap 1978; 204:1-10

4. Carlsson A, Lindquist M: Effect of ethanol on the hydroxylation of tyrosine and tryptophan in the rat brain in vivo. J Pharm Pharmacol 1972; 25:437-440

5. Carlsson A, Magnusson J, Svensson TH, Waldeck B: Effect of ethanol on the metabolism of brain catecholamines. Psychopharmacologica 1973; 30:27-36

6. Corrodi H, Fuxe K, Hokfelt T: The effect of ethanol on the activity of central catecholamine neurons in rat brain. J Pharm Pharmacol 1966; 18:821-823

7. Bustos G, Roth RH: Effect of acute ethanol treatment on transmitter synthesis and metabolism in central dopaminergic neurons. J Pharm Pharmacol 1976; 28:580582

8. Tabakoff B, Hoffman PL: Alterations in receptors controlling dopamine synthesis after chronic ethanol ingestion. J Neurochem 1978; 31:1223-1229

9. Griffiths PJ, Littleton JM, Ortiz A: Changes in monoamine concentrations in mouse brain associated with ethanol dependence and withdrawal. $\mathrm{Br} \mathrm{J}$ Pharmacol 1974; 50:489-798

10. Wajda IJ, Magnigault I, Hudick P: Dopamine levels in the striatum and the effect of alcohol and reserpine. Biochem Pharmacol 1977; 26:653-655

11. Black RF, Hoffman PL, Tabakoff B: Receptor-mediated dopaminergic function after ethanol withdrawal. Alcoholism: Clin Exp Res 1980; 4:294-297

12. Tabakoff B, Black RF: A high performance liquid chromatography method for 
measuring brain dihydroxyphenylalanine levels and dopamine synthesis rates. J Neurochem 1980; 34:1707-1711

13. Engel J, Liljequist S: The effect of long-term ethanol treatment on sensitivity of the dopamine receptors in the nucleus accumbens. Psychopharmacol 1976; 49:253257

14. Seeman P, Lee T: The dopamine releasing actions of neuroleptics and ethanol. J Pharmacol Exp Therap 1974; 190:131-140

15. Goldstein DS, Pal N: Alcohol dependence produced in mice by inhalation of ethanol: grading the withdrawal reaction. Science $1971 ; 172: 288-290$

16. Goldstein DS: Inhalation of ethanol vapor, in Alcohol Tolerance and Dependence. Edited by Rigter H, Crabbe JC. Elsevier, Amsterdam, 1980, pp 81-92

17. Roach MK, Khan MM, Coffman R, Pennington W, Davis DL: Brain $\left(\mathrm{Na}^{+}+\mathrm{K}^{+}\right)$activated adenosine triphosphatase activity and neurotransmitter uptake in alcoholdependent rats. Brain Res 1973; 63:323-329

18. Friedman $\mathrm{HJ}$ : Assessment of physical dependence on and withdrawal from ethanol in animals, in Alcohol Tolerance and Dependence. Edited by Riger H, Crabbe JC. Elsevier, Amsterdam, 1980, pp 93-121

19. Ritzmann RF, Tabakoff B: Body temperature in mice: a quantitative measure of alcohol tolerance and physical dependence. J Pharmacol Exp Therap 1976; 199:158-170

20. Tabakoff B, Anderson RA, Ritxmann RF: Brain acetylaldehyde after ethanol administration. Biochem Pharmacol 1976; 25:1305-1309

21. Kacmarek RM, Dimas S, Mack CW: The Essentials of Respiratory Therapy. Chicago, Year Book Medical Publishers, 1979, p. 359

22. Kehr W, Carlsson A, Lindqvist M: A method for determination of 3,4-dihydroxyphenyalanine (DOPA) in brain. N-S Arch Pharmacol 1972; 274:273-280

23. Rogers J, Wiener SG, Bloom FE: Long-term ethanol administration methods for rats: Advantages of inhalation over intubation or liquid diets. Behav Neural Biol $1979 ; 27: 466-486$

24. Roth RH, Murrin C, Walters JR: Central dopaminergic neurons: effects of alterations in impulse flow on the accumulation of dihydroxyphenylacetic acid. Europ J Pharmacol 1976; 36:163-171

25. Ritzmann RF, Tabakoff B: Strain differences in the development of acute tolerance to ethanol, in Biological Effects of Alcohol. Edited by Regleiter H. Plenum Publishing, 1980, pp 197-210 